\title{
DOPING KNOWLEDGE, BELIEFS AND PRACTICES AMONG PHYSIOTHERAPISTS
}

\section{Wajeeha $^{1,2 \otimes}$, Ahsan Javed'}

\begin{abstract}
OBJECTIVES: To study the knowledge, beliefs and practices of doping in sports among physiotherapists.

METHODS: This cross-sectional study was conducted amongst 390 physiotherapists working in different hospitals/clinics and teaching universities of Lahore with response rate of $94.61 \%(n=369)$. Modified Doping Use Belief tool was used to assess beliefs regarding use of performance enhancement drugs, other questions were used to check doping knowledge and practice of these drugs. SPSS v22.0 was used to analyze the data.
\end{abstract}

RESULTS: Out of 369 respondents, 272 (73.7\%) were females and 97 (26.3\%) were males. Mean age was $27 \pm 4.4$ years. In general knowledge about doping, 196 (53.1\%) never studied sports course, $238(64.5 \%)$ had no information about doping, 204 (55.3\%) were not aware of banned substances, and 312 (84.6\%) had information through media. Specifically about doping, 240 (65\%), 174 (47.3\%), $250(67.7 \%), 238(64.5 \%)$, and 229 (62.1\%) had no knowledge about prohibited list, therapeutic use exemptions, procedures of anti-doping testing, anti-doping rule violation, and sanctions on anti-doping rule violations respectively. Majority $(n=238 ; 64.5 \%)$ had scarcity of knowledge about health risks related to doping. Regarding beliefs, $28 \mathrm{I}(76.2 \%)$ and $259(70.2 \%)$ had a disagreement on belief that performance-enhancing drugs/methods should be allowed for top-level athletes and all athletes respectively. In practice, 347 (94\%) never offered any doping agent and 3 । $4(85.1 \%)$ never had any experience with doping drugs.

CONCLUSION: Physiotherapists had a low knowledge on doping. Majority of respondents showed positive belief of non-use of doping agents, and in practice majority had never practiced doping drugs.

KEY WORDS: Beliefs (MeSH); Doping in Sports (MeSH); Knowledge (MeSH); Practices (Non-MeSH); Physical Therapists (MeSH).

THIS ARTICLE MAY BE CITED AS: Wajeeha, Javed A. Doping knowledge, beliefs and practices among physiotherapists. Khyber Med Univ J 2020; I2(3):234-7. DOI: I0.35845/kmuj.2020.19718.

\section{INTRODUCTION}

$\mathrm{D}$ ping is a common and well-known phenomenon in the field of sports. Natural performance enhancement substances had been used by athletes over 5,000 years ago. In past, ephedra was used as common doped agent, in China while in Ancient Greek Olympic Games, dried figs and mushrooms were common. Roman gladiators and medieval knights were also familiar with the usage of it. ${ }^{1,2}$ The word doping derived from 'dop' that refers to use of stimulant drink in South African tribal ceremonies during $18^{\text {th }}$ century. Doping is employment of different prohibited drugs or adaptation of different illegal methods by athletes to improve their performance without considering the violation of anti-doping rules set by World Anti-Doping Agency (WADA). It is not only considered unethical and illegal but also leads to irreversible health hazards. ${ }^{2-4}$

In 20I5, a review was conducted on prevalence of doping in elite sports, which projects that about $14-39 \%$ athletes use different kinds of doping agents for performance enhancement intentionally. Mainly they use to get a competitive edge over opponent. ${ }^{5}$ The protection of health of the athlete is key objective in any sports. For fulfillment of this goal, team of physicians, coaches, and physiotherapists collectively work on it and maintain the integrity of the competition. In today's sports, there are many issues like dietary intake, performance enhancement, health
I. Department of Physical Therapy, University of South Asia, Cantt Campus, Lahore, Pakistan.

2. Department of Physical Therapy, Faculty of Health Sciences, University of Health Sciences, Lahore, Pakistan. Email ${ }^{凶}$ :wajeeha_z@yahoo.com Contact \# : +92-323-4500788

$\begin{array}{ll}\text { Date Submitted: } & \text { September 20, } 2019 \\ \text { Date Revised: } & \text { June 18, 2020 } \\ \text { Date Accepted: } & \text { July 04, 2020 }\end{array}$

management, and use of prohibited substances. Doping is one of highlighted issues in sports and different programs are offered for its management. ${ }^{6}$ To address any issue in society, knowledge-practicebelief model plays a very important role. There is interconnected relationship of knowledge production, conservation and its transmission. Knowledge systems consist of critical complex of knowledgepractice-belief model. ${ }^{7}$ In 2014, a metaanalysis was conducted by Ntoumanis et. al, on personal and psychosocial predictors of doping in physical activity concluded that there is positive correlation between attitude and doping behaviors. Attitude is considered as main index of doping behavior by psychosocial approach. ${ }^{8}$

Doctors are part of sport's teams and deals with medical issues of athletes. They must be educated enough about drugs prescription by guidelines provided by World Anti-Doping Code (WADC). ${ }^{6}$ A study concluded that the therapeutic use exemption (TUE) is also a problem in antidoping policy. About $85 \%$ of athletes used TUE as necessary to win from other athletes and $51 \%$ believed that use of TUE is common even without medical need. ${ }^{9}$ In elite sports, about $40 \%$ to $100 \%$ athletes use different type of nutritional supplements depending on type of sports, needs of athletes and level of competition. These supplements may expose the athletes to precursor of anti-doping or prohibited substances which may lead to violate anti-doping regulations in sports. It is important to educate athletes to use World Anti-Doping Agency (WADA) certified laboratory tested supplementary 
TABLE I: GENERAL KNOWLEDGE OF PHYSIOTHERAPISTS ABOUT DOPING

\begin{tabular}{|l|l|c|c|}
\hline \multicolumn{2}{|c|}{ Characteristics } & $\begin{array}{c}\text { Frequency } \\
(\mathbf{n = 3 6 9 )}\end{array}$ & Percentage \\
\hline \multirow{2}{*}{ Studied sports course } & Yes & 173 & 46.9 \\
\cline { 2 - 4 } & No & 196 & 53.1 \\
\hline \multirow{2}{*}{ Information about doping } & Yes & 131 & 35.5 \\
\cline { 2 - 4 } & No & 238 & 64.5 \\
\hline \multirow{2}{*}{$\begin{array}{l}\text { Information of banned } \\
\text { substances }\end{array}$} & Yes & 165 & 44.7 \\
\hline \multirow{3}{*}{ Source of information } & No & 204 & 55.3 \\
\cline { 2 - 4 } & Media & 312 & 84.6 \\
\cline { 2 - 4 } & Colleagues & 10 & 2.7 \\
\cline { 2 - 4 } & Teachers & 10 & 2.7 \\
\cline { 2 - 4 } & Syllabus books & 26 & 3 \\
\cline { 2 - 4 } & None & 11 & 7 \\
\hline
\end{tabular}

TABLE II: SPECIFIC KNOWLEDGE OF DOPING AMONG PHYSIOTHERAPISTS

\begin{tabular}{|l|c|c|c|}
\hline \multicolumn{1}{|c|}{ Variables } & $\begin{array}{c}\text { To a larger } \\
\text { extent } \mathbf{n}(\%)\end{array}$ & $\begin{array}{c}\text { To some } \\
\text { extent } \mathbf{n}(\%)\end{array}$ & $\begin{array}{c}\text { No } \\
\mathbf{n}(\%)\end{array}$ \\
\hline The prohibited list & $\mathrm{II}(3)$ & $\mathrm{I}$ I8 (32) & $240(65)$ \\
\hline Therapeutic use exemptions & $\mathrm{II}(3)$ & $\mathrm{I} 84(49.9)$ & $\mathrm{I} 74(47.3)$ \\
\hline Procedures of anti-doping testing & $\mathrm{II}(3)$ & $\mathrm{I} 08(29.3)$ & $250(67.7)$ \\
\hline Health risks related to doping & $43(\mathrm{II} .7)$ & $238(64.5)$ & $88(23.8)$ \\
\hline Anti-doping rule violations & $\mathrm{II}(3)$ & $\mathrm{I} 20(32.5)$ & $238(64.5)$ \\
\hline Sanctions on anti-doping rule violations & $\mathrm{II}(3)$ & $\mathrm{I} 29(35)$ & $229(62 . \mathrm{I})$ \\
\hline
\end{tabular}

\section{TABLE III: DOPING USING BELIEFS (DUB)} AMONG PHYSIOTHERAPISTS

\begin{tabular}{|l|c|c|c|}
\hline \multicolumn{1}{|c|}{ Variables } & $\begin{array}{c}\text { Yes, without } \\
\text { restriction } \\
\mathbf{n}(\%)\end{array}$ & $\begin{array}{c}\text { Yes, but with } \\
\text { restriction } \\
\mathbf{n}(\%)\end{array}$ & $\begin{array}{c}\text { Absolutely } \\
\text { not } \\
\mathbf{n}(\%)\end{array}$ \\
\hline $\begin{array}{l}\text { Do you believe that performance- } \\
\text { enhancing drugs/methods should be } \\
\text { allowed for top level athletes? }\end{array}$ & I I (3) & $77(20.8)$ & 28 I (76.2) \\
\hline $\begin{array}{l}\text { Do you believe that performance- } \\
\text { enhancing drugs/methods should be } \\
\text { allowed for all athletes? }\end{array}$ & II (3) & $99(26.8)$ & $259(70.2)$ \\
\hline
\end{tabular}

products. ${ }^{10}$ Team of health professionals must be cognizant of all rules of antidoping while dealing with athletes." Mostly coaches are cited as precipitating or preventing role in engagement of athlete in doping. Their role can be supported in anti-doing stance but also insufficient to ensure action. Analysis of coaches reflective conversations, the issues set by the coaches differed and influenced subsequent actions and evaluations. ${ }^{12}$

Nowadays physiotherapists have become an important and essential part of the sports teams in preparation of athletes in providing treatment and rehabilitation of injuries, maintenance and recovery the field of sports physiotherapy, physiotherapists must be aware of this delicate topic of doping. Despite knowing the importance of physiotherapy in sports, there is little known about the physiotherapists knowledge on doping agents, methods, rules and regulations and sanctions in case of violations or their perception about doping practices in our set up. The main purpose of this study was to find out the knowledge, beliefs, and practices of doping among interventions. ${ }^{13}$ With emerging trends in physiotherapists working in various hospitals, clinics and teaching universities of Lahore, Pakistan.

\section{METHODS}

This cross-sectional study was conducted on sample size of 390 sports physiotherapists from September 2016 to February 2017 after taking ethical approval from Ethical Review Board of University of Health Sciences, Lahore. Data was collected by convenient sampling technique from physiotherapists working in different government/private hospitals and teaching universities (t-DPT section, University of Health Sciences, Lahore; Postgraduate section of Riphah International University, Lahore Campus; Al Shifa Hospital, Lahore, Mayo hospital, Lahore, Children hospital, Lahore; Furqan Hospital, Lahore; Surrya Azeem Hospital, Lahore; Haq Orthopedics Hospital; Mid City Hospital, Lahore; OMC Hospital; School of Physiotherapy, Mayo Hospital, Lahore) and private clinics set-ups in Lahore. Physiotherapists, who had their last degree from any one of these,: BSPT, DPT, t-DPT, PP-DPT, MS, M. Phil and having experience more than I year were included in this study. Out of the total 390 respondents who were approached for data collection, 369 respondents consented and gave completely filled the self-administered proformas, resulting in a response rate of $94.61 \%$.

In proforma, first part was about the sociodemographic characteristics of the respondent's like age, gender, marital status, educational status and working setups of respondent's, the second part was about doping knowledge. ${ }^{14}$ The third part was a Modified tool about Doping Use Belief (DUB). Doping Use Belief measures (DUB) is defined as expressions of the presumed opinion regarding doping i.e., whether doping should be allowed for top and all level athletes (2 separate questions). Respondents were asked to select one of the 3 responses: 'yes, without restrictions', 'yes, with restrictions' and 'absolutely not', ${ }^{15}$ The doping practices were measured by two responses of doping behavior, i.e. current use of and past experience with performance enhancing substances/methods.

Sociodemographic characteristics of the respondents were the independent variables. While doping knowledge doping beliefs and doping practices were dependent variables. Descriptive 
statistics like mean, standard deviation, frequency and percentages were calculated for all the variables. Data was presented as tables and graphs using Statistical Package for Social Sciences version 22.

\section{RESULTS}

Out of 369 respondents, 272 (73.7\%) were females and $97(26.3 \%)$ were males. Mean age was $27 \pm 4.4$ years. Among all respondents, three fourth were working in different private hospitals and clinics. A large proportion of respondents 261 $(70.7 \%)$ were graduates and currently enrolled in different post-graduation courses.

When asked about knowledge regarding doping, 196 (53.1\%) never studied sports course and among all only I 3 I (35.5\%) have some idea about doping, 165 (44.7\%) have any knowledge regarding banned substances and media was the main source of this information (Table l).

A large number of respondents $(n=240$; $65 \%$ ) were unaware of the list of prohibited drugs and 184 (49.9\%) respondents had some knowledge about therapeutic uses of doping while 250 $(67.7 \%)$ had no knowledge about the procedure of anti-doping test. About $64.5 \%(n=238)$ of the respondents were ignorant to anti-doping rule violations and $62.1 \%(n=229)$ were unaware of the sanctions given to the athletes using different doping drugs (Table II).

About $76.2 \%(n=28 I) \& 70.2 \%(n=259)$ showed positive belief of non-use of performance-enhancing drugs/methods for top-level athletes and for all athletes respectively (Table III). Upon asking about practice regarding doping, 347 (94\%) had never been offered any doping agent and $3 \mid 4(85.1 \%)$ never had any experience with doping drugs respectively.

\section{DISCUSSION}

The aim of the study was to find the level of knowledge and the practices of doping among the physiotherapists as well as their beliefs about its use in athletes. Most of the respondents had a mean age of $27 \pm 4.4$ years. Most either did not study the sports course during their study program or were unaware of the doping rules regulations and guidelines. The findings of this study were consistent with the findings of a study conducted by Morente-Sánchez J, Zabala M in 2015 on technical staff of football, among that about $57.6 \%$ were not familiar with WADA and $89.9 \%$ did not know prohibited list of drugs and supplements. ${ }^{16}$ Results of the study were inconsistent with the study done in Uganda, Doping Use Belief (DUB) opinion regarding doping i.e., whether doping should be allowed for top and all level athletes measures $82.5 \%$ and $81.0 \%$ respectively and in this study majority of the respondents discourage use of doping for top and all level athletes $76.2 \%$ and $70.2 \%$ respectively. In contrast the major source of information was their colleague while in study media was the main source of information. ${ }^{14}$

The study concluded that compulsion for anti-doping education and stoppage programs for all the members of health professionals, not just athletes only. Medical professionals were not the sufficient source of doping information and educational institutes should start and develop educational programs for prevention of doping and more efficient educational strategies and better controls are needed. It is important to find out knowledge prevalence and the magnitude of doping problem in our region, as no data were reported previously. In this study, respondents personally did not have any experience of doping during the sports and the awareness about it was too low among the respondents. Moreover, many of the respondents never used or prescribed any performance enhancing drugs to other players as they were unaware of the advantages and the disadvantages of doping. Results are consistent with the recommendations of Matosic et al., $2016^{17}$ who concluded that efforts to lessen the hazards of doping are less. There must be some researches on stoppage of doping and coaches or trainers must have a positive attitudes towards doping as they are the source of better guideline to the athletes.

A study conducted by $D$ Hauw and $S$ Mohamed concluded that doping behavior of athlete is totally influenced by its knowledge, it plays very important role in development of efficient and workable strategies for prevention of doping, doping behavior is measured by level of knowledge and attitudes with regard to sports. ${ }^{18}$ To the best of our knowledge, it is the first study on the knowledge, beliefs and practices of physiotherapists towards doping in this region. The results of this study cannot be generalized to other regions. The study has limitation of responder recall biasness and future study must be conducted on physiotherapist who are involved in direct rehabilitation in the field of sports.

\section{CONCLUSION}

Physiotherapists had a low level of general and specific knowledge on doping. Majority of respondents showed positive belief of non-usage of doping agents, and in practice majority had never practiced doping drugs. Although the respondents had limited knowledge about prohibited substances, the advantages and disadvantages were appreciated by all.

\section{REFERENCES}

I. Kim T, Kim YH. Korean national athletes' knowledge, practices, and attitudes of doping: a cross-sectional study. Subst Abuse Treat Prev Policy 2017;12:7. DOII0.1I86/s।30II-0170092-7.

2. Manouchehr J, Tojari F. Development and validation of instruments to measure doping attitudes and doping beliefs. Euro J Exp Bio 20 I3;3(2): I836.

3. Bae M, Yoon J, Kang H, Kim T. Influences of perfectionism and motivational climate on attitudes towards doping among Korean national athletes: A cross sectional study. Subst Abuse Treat Prev Policy 2017;12:52. DOI: 10.1I86/s/30II$017-0138-x$

4. Murofushi Y, Kawata Y, Kamimura A, Hirosawa M, Shibata N. Impact of anti-doping education and doping control experience on anti-doping knowledge in Japanese university athletes: a cross-sectional study. Subst Abuse Treat Prev Policy 20I8; I3(I):44. DOI: $10.1186 / \mathrm{s}$ |30||-0|8-0|78-x.

5. Muwonge H, Zavuga R, Kabenge PA, Makubuya T. Nutritional supplement practices of professional Ugandan athletes: a cross-sectional study. J Int Soc Sports Nutr 2017;14:4I. DOI: |0.| |86/s | 2970-0|7-0|98-3.

6. Morente-Sanchez J, Zabala M. Doping in sport: a review of elite athletes' attitudes, beliefs, and knowledge. Sports Med 20I3; 43(6):395-4II. DOI: 10. 1007/s 40279-013-0037-x.

7. Constant NL, Tshisikhawe MP. Hierarchies of knowledge: ethnobotanical knowledge, practices 
and beliefs of the Vhavenda in South Africa for biodiversity conservation. J Ethnobiol Ethnomed 2018;14(I): 56. DOI: I0. I |86/s | 3002-0|8-0255-2.

8. Ntoumanis N, Ng JY, Barkoukis V, Backhouse S. Personal and psychosocial predictors of doping use in physical activity settings: a metaanalysis. Sports Med 20I4; 44(II): |603-24. DOI: |0.1007/s 40279-0|40240-4.

9. Overbye M, Wagner U. Between medical treatment and performance enhancement: an investigation of how elite athletes experience Therapeutic Use Exemptions. Int J Drug Policy 2013;24(6):579-88. DOI: 10.1016/ j.drugpo.2013.03.007.

10. Garthe I, Maughan RJ. Athletes and Supplements: Prevalence and Perspectives. Int J Sport Nutr Exe 2018;28(2):126-38. DOI: 10. II23/ijsnem.2017-0429.

II. Tandon S, Bowers LD, Fedoruk MN.
Treating the elite athlete: anti-doping information for the health professional. Mo Med 2015; II2(2): 122-8.

12. Allen JB, Morris R, Dimeo P, Robinson L. Precipitating or prohibiting factor: Coaches' perceptions of their role and actions in anti-doping. Int J Sports Sci Coach 2017;12(5):577-87. DOI: 10. II77/ 1747954|I7727653.

13. Grant M-E, Steffen K, Glasgow P, Phillips N, Booth L, Galligan M. The role of sports physiotherapy at the London 2012 Olympic Games. Br J Sports Med 20I4;48(I):63-70. DOI: I0.1 I36/bjsports-2013-093169.

14. Muwonge H, Zavuga R, Kabenge PA. Doping knowledge, attitudes, and practices of Ugandan athletes': a cross-sectional study. Subst Abuse Treat Prev Policy 2015;10:37. DOI: I0.II86/sI30II-0I5-0033-2.

15. Petróczi A. Attitudes and doping: a structural equation analysis of the relationship between athletes' attitudes, sport orientation and doping behaviour. Subst Abuse Treat Prev Policy 2007;2:34. DOI: I0. I I86/ 1747-597X-2-34.

16. Morente-Sanchez J, Zabala M. Knowledge, attitudes and beliefs of technical staff towards doping in Spanish football. J Sports Sci 2015;33(I2): | 267-75. DOI: I0. 1080/ $026404 \mid 4.2014 .999699$.

17. Matosic D, Ntoumanis N, Boardley ID, Stenling A, Sedikides C. Linking narcissism, motivation, and doping attitudes in sport: A multilevel investigation involving coaches and athletes. J Sport Exercise Psy 2016; 38(6):556-66. DOI: 10.1123/jsep. 2016-0141.

18. Hauw D, Mohamed S. Patterns in the situated activity of substance use in the careers of elite doping athletes. Psychol Sport Exerc 2015;16(2015): I56-63. DOI: 10.1016/j.psychsport. 2013.09.005.

\section{AUTHORS' CONTRIBUTIONS}

Following authors have made substantial contributions to the manuscript as under:

Wa: Conception, acquisition, analysis and interpretation of data, drafting the manuscript, critical review, final approval of the version to be published

AJ: Study design, analysis and interpretation of data, drafting the manuscript, final approval of the version to be published

Authors agree to be accountable for all aspects of the work in ensuring that questions related to the accuracy or integrity of any part of the work are appropriately investigated and resolved.

\begin{tabular}{|c|}
\hline CONFLICT OF INTEREST \\
Authors declared no conflict of interest \\
GRANT SUPPORT AND FINANCIAL DISCLOSURE \\
NIL
\end{tabular}

\section{DATA SHARING STATEMENT}

The data that support the findings of this study are available from the corresponding author upon reasonable request
KMUJ web address: www.kmuj.kmu.edu.pk

Email address: kmuj@kmu.edu.pk 